American Journal of Applied Sciences 7 (7): 969-975, 2010

ISSN 1546-9239

(C) 2010 Science Publications

\title{
Approximation of Iteration Number for Gauss-Seidel Using Redlich-Kister Polynomial
}

\author{
${ }^{1}$ M.K. Hasan, ${ }^{2}$ J. Sulaiman, ${ }^{3}$ S. Ahmad, ${ }^{4}$ M. Othman and ${ }^{5}$ S.A.A. Karim \\ ${ }^{1}$ Industrial Informatic Programme, University Kebangsaan Malaysia, \\ 43600 UKM Bangi, Selangor, Malaysia \\ ${ }^{2}$ Mathematics with Economics Programme, University Malaysia Sabah, Locked bag 2073, \\ 88999 Kota Kinabalu, Sabah, Malaysia \\ ${ }^{3}$ Department of Mathematic Science, University Malaysia Terengganu, \\ 21030 Kuala Terengganu, Terengganu, Malaysia \\ ${ }^{4}$ Department of Communication Technology and Networks, University Putra Malaysia, \\ 43400 UPM Serdang, Selangor, Malaysia \\ ${ }^{5}$ Department of Fundamental and Applied Science, University Technology Petronas, \\ Bandar Seri Iskandar, 31750 Tronoh, Perak, Malaysia
}

\begin{abstract}
Problem statement: Development of mathematical models based on set of observed data plays a crucial role to describe and predict any phenomena in science, engineering and economics. Therefore, the main purpose of this study was to compare the efficiency of Arithmetic Mean (AM), Geometric Mean (GM) and Explicit Group (EG) iterative methods to solve system of linear equations via estimation of unknown parameters in linear models. Approach: The system of linear equations for linear models generated by using least square method based on $(m+1)$ set of observed data for number of Gauss-Seidel iteration from various grid sizes. Actually there were two types of linear models considered such as piece-wise linear polynomial and piece-wise Redlich-Kister polynomial. All unknown parameters of these models estimated and calculated by using three proposed iterative methods. Results: Thorough several implementations of numerical experiments, the accuracy for formulations of two proposed models had shown that the use of the third-order Redlich-Kister polynomial has high accuracy compared to linear polynomial case. Conclusion: The efficiency of AM and GM iterative methods based on the Redlich-Kister polynomial is superior as compared to EG iterative method.
\end{abstract}

Key words: Arithmetic mean, geometric mean, explicit group, Redlich-Kister model, Poisson equation

\section{INTRODUCTION}

Group Explicit iterative method has been formulated and proposed by Evans (1985). Further investigation and implementation of this method are done by Evans and Yousif (1986; 1990); Yousif and Evans (1986; 1998) and Jumat and Abdullah (2001). The method is then modified by Abdullah (1991) using half-sweep concept and produced Explicit Decoupled Group (EDG) method. The EDG methods have been further implemented by Ibrahim and Abdullah (1995); Yousif and Evans (1995), Jumat and Abdullah (1999) and Sulaiman et al. (2007). Beside that, Othman and Abdullah (2000a; 2000b) proposed a new variant of EG method called the Modified Explicit Group (MEG).
This method implements the quarter-sweep concept to the EG method.

Arithmetic Mean (AM) and Geometric Mean (GM) schemes are methods that are categorized in two-step iterative type. From its literature, Ruggiero and Galligani (1990) is the first to propose the AM method. This method has the same computational molecule to Iterative Alternating Decomposition Explicit (IADE) proposed by Sahimi and Khatim (2001) but different in their parameter coefficient. However, the implementation of the first step formulation and second step formulation is absolutely different.

Sulaiman et al. (2004) combined the AM method with the half-sweep concept to develop the Half-Sweep Arithmetic Mean (HSAM). Further investigation to this

Corresponding Author: M.K. Hasan, Industrial Informatic Programme, University Kebangsaan Malaysia, 43600 UKM Bangi, Selangor, Malaysia 
Am. J. Applied Sci., 7 (7): 969-975, 2010

method can be found in Sulaiman et al. (2005a; 2005b). In fact, Geometric Mean (GM) method is another alternative to AM method. Sulaiman et al. (2006a) also proposed the Half-Sweep Geometric Mean (HSGM) to solve two point boundary value problems. The method is further investigated by Sulaiman et al. (2006b) to solve water quality model and Muthuvalu and Sulaiman (2008) for solving linear Fredholm Equations.

In this study, we will implement the EG, AM and GM methods to estimate the unknown parameters via solving system of linear equations. The system of linear equations is generated using the least square method on $(m+1)$ set of observed data. Here, only two types of linear models will be considered, which are the piecewise linear polynomial (Linear) and piece-wise Redlich-Kister polynomial (RK).

\section{MATERIALS AND METHODS}

Generating system of linear equations: To generate the system of linear equations, consider $(m+1)$ data set produced via simulation given in Table 1 .

As mentioned before, in this study we only consider the piece-wise linear polynomial and RedlichKister polynomial. The piece-wise linear polynomial and the third-order piece-wise Redlich-Kister polynomial are given respectively as follows:

$\mathrm{y}_{1 \mathrm{k}}(\mathrm{X})=\mathrm{S}_{2 \mathrm{k}-1}+\mathrm{S}_{2 \mathrm{k}} \mathrm{X}+\mathrm{e}_{\mathrm{k}}, \quad \mathrm{X} \in\left[\mathrm{X}_{\mathrm{k}}, \mathrm{X}_{\mathrm{k}+1}\right]$

and:

$\mathrm{y}_{3 \mathrm{k}}(\mathrm{X})=\mathrm{X}(1-\mathrm{X})\left(\mathrm{S}_{2 \mathrm{k}-1}+\mathrm{S}_{2 \mathrm{k}}(2 \mathrm{X}-1)\right)+\mathrm{e}_{\mathrm{k}}$,

$\mathrm{X} \in\left[\mathrm{X}_{\mathrm{k}}, \mathrm{X}_{\mathrm{k}+1}\right]$

Where:

$\mathrm{X}_{\mathrm{k}}=\mathrm{k}^{\text {th }}$ matrix size

$Y_{k}=$ GS number of iterations for $\mathrm{k}^{\text {th }}$ matrix size

$\mathrm{e}_{\mathrm{k}}=\mathrm{k}^{\text {th }}$ random error

for $\mathrm{k}=1,2,3, \ldots, \mathrm{m}, \mathrm{m}+1$ and $\mathrm{S}_{\mathrm{i}} \mathrm{i}=1,, 2,3, \ldots,(\mathrm{n}=2 \mathrm{~m})$, are the unknown parameters which will be estimated. To generate the system of linear equation from observed data, $\left(\mathrm{X}_{\mathrm{k}}, \mathrm{Y}_{\mathrm{k}}\right), \mathrm{i}=1,, 2,3, \ldots, \mathrm{m}, \mathrm{m}+1$, both Eq. 1 and 2 can be rewritten as:

$$
\begin{aligned}
& \mathrm{y}_{\mathrm{k}}(\mathrm{X})=\mathrm{N}_{1}^{\mathrm{k}}(\mathrm{X}) \mathrm{S}_{2 \mathrm{k}-1}+\mathrm{N}_{2}^{\mathrm{k}}(\mathrm{X}) \mathrm{S}_{2 \mathrm{k}}+\mathrm{e}_{\mathrm{k}}, \\
& \mathrm{X} \in\left[\mathrm{X}_{\mathrm{k}}, \mathrm{X}_{\mathrm{k}+1}\right]
\end{aligned}
$$

Meanwhile, the function $\mathrm{N}_{\mathrm{t}}^{\mathrm{k}}(\mathrm{x}), \mathrm{t}=1,2$ for both Model 1 and 2 are given as follows:

$$
\left.\begin{array}{r}
\mathrm{N}_{1}^{\mathrm{k}}(\mathrm{X})=1, \\
\mathrm{~N}_{2}^{\mathrm{k}}(\mathrm{X})=\mathrm{X},
\end{array}\right\}, \quad \mathrm{X} \in\left[\mathrm{X}_{\mathrm{k}}, \mathrm{X}_{\mathrm{k}+1}\right]
$$

Table 1: Relation between matrix size and number of iterations for Gauss-Seidel to solve one dimensional Poisson problem

\begin{tabular}{lll}
\hline $\mathrm{K}$ & Matrix size & No. of Iterations \\
\hline 1 & $\mathrm{X}_{1}$ & $\mathrm{Y}_{1}$ \\
2 & $\mathrm{X}_{2}$ & $\mathrm{Y}_{2}$ \\
3 & $\mathrm{X}_{3}$ & $\mathrm{Y}_{3}$ \\
$\vdots$ & $\vdots$ & $\vdots$ \\
$\mathrm{m}$ & $\mathrm{X}_{\mathrm{m}}$ & $\mathrm{Y}_{\mathrm{m}}$ \\
$\mathrm{m}+1$ & $\mathrm{X}_{\mathrm{m}+1}$ & $\mathrm{Y}_{\mathrm{m}+1}$ \\
\hline
\end{tabular}

and

$\left.\begin{array}{c}N_{1}^{k}(X)=X-X^{2}, \\ N_{2}^{k}(X)=3 X^{2}-X-2 X^{3},\end{array}\right\}, \quad X \in\left[X_{k}, X_{k+1}\right]$

Assuming that values between data interval are equal, thus:

$$
\begin{aligned}
& Y_{k-1}\left(X_{k}\right) \approx N_{1}^{k-1}\left(X_{k}\right) S_{2 k-1}+N_{2}^{k-1}\left(X_{k}\right) S_{2 k}, \\
& X_{k} \in\left[X_{k-1}, X_{k}\right] \\
& Y_{k}\left(X_{k}\right) \approx N_{1}^{k}\left(X_{k}\right) S_{2 k-1}+N_{2}^{k}\left(X_{k}\right) S_{2 k}, \\
& X \in\left[X_{k}, X_{k+1}\right]
\end{aligned}
$$

The random error $\mathrm{e}_{\mathrm{k}}, \mathrm{k}=1,2,3, \cdots, \mathrm{m}, \mathrm{m}+1$ can be defined as follows:

$$
e_{k}=\left\{\begin{array}{cc}
Y_{1}-N_{1,1}^{1} S_{1}-N_{2,1}^{1} S_{2}, & k=1 \\
Y_{m+1}-N_{1, m+1}^{m} S_{2 m-1}-N_{2, m+1}^{m} S_{2 m}, & k=m+1 \\
Y_{k}-N_{1, k}^{k-1} S_{2 k-3}-N_{2, k}^{k-1} S_{2 k-2}- & k \neq 1, m+1 \\
N_{1, k}^{k} S_{2 k-1}-N_{2, k}^{k} S_{2 k}, &
\end{array}\right.
$$

where, $N_{t}^{k}\left(X_{p}\right), t, p=1,2$ is denoted as $N_{t, p}^{k}$. Next, we estimate the $S_{i} i=1,2,3, \cdots,(n=2 m)$, which minimized:

$\mathrm{H}=\sum_{\mathrm{k}=1}^{\mathrm{m}+1} \mathrm{e}_{\mathrm{k}}^{2}$

Thus, Eq. 9 has to satisfy Eq. 10:

$\frac{\partial \mathrm{H}}{\partial \mathrm{S}_{\mathrm{i}}}, \mathrm{i}=1,2,3, \cdots, 2 \mathrm{~m}$,

Eq. 10 will be used to generate system of linear equation in the form of matrix. The general form of generated matrix for the case of $\mathrm{m}=10$ is given by:

$\mathrm{RS}=\underset{\sim}{\mathrm{F}}$

Where: 


$$
\mathbf{R}=\left[\begin{array}{llllllllll}
\mathrm{R}_{1,1} & \mathrm{R}_{1,2} & \mathrm{R}_{1,3} & \mathrm{R}_{1,4} & & & & & & \\
\mathrm{R}_{2,1} & \mathrm{R}_{2,2} & \mathrm{R}_{2,3} & \mathrm{R}_{2,4} & & & & & & \\
\mathrm{R}_{3,1} & \mathrm{R}_{3,2} & \mathrm{R}_{3,3} & \mathrm{R}_{3,4} & \mathrm{R}_{3,5} & \mathrm{R}_{3,6} & & & & \\
\mathrm{R}_{4,1} & \mathrm{R}_{4,2} & \mathrm{R}_{4,3} & \mathrm{R}_{4,4} & \mathrm{R}_{4,5} & \mathrm{R}_{4,6} & & & & \\
& & \mathrm{R}_{5,3} & \mathrm{R}_{5,4} & \mathrm{R}_{5,5} & \mathrm{R}_{5,6} & \mathrm{R}_{5,7} & \mathrm{R}_{5,8} & & \\
& & \mathrm{R}_{6,3} & \mathrm{R}_{6,4} & \mathrm{R}_{6,5} & \mathrm{R}_{6,6} & \mathrm{R}_{6,7} & \mathrm{R}_{6,8} & & \\
& & & & \mathrm{R}_{7,5} & \mathrm{R}_{7,6} & \mathrm{R}_{7,7} & \mathrm{R}_{7,8} & \mathrm{R}_{7,9} & \mathrm{R}_{7,10} \\
& & & & \mathrm{R}_{8,5} & \mathrm{R}_{8,6} & \mathrm{R}_{8,7} & \mathrm{R}_{8,8} & \mathrm{R}_{8,9} & \mathrm{R}_{8,10} \\
& & & & & & \mathrm{R}_{9,7} & \mathrm{R}_{9,8} & \mathrm{R}_{9,9} & \mathrm{R}_{9,10} \\
& & & & & & \mathrm{R}_{10,7} & \mathrm{R}_{10,8} & \mathrm{R}_{10,9} & \mathrm{R}_{10,10}
\end{array}\right]_{(10 \times 10)}
$$

$\mathrm{S}=\left[\begin{array}{llllllllll}\mathrm{S}_{1} & \mathrm{~S}_{2} & \mathrm{~S}_{3} & \mathrm{~S}_{4} & \mathrm{~S}_{5} & \mathrm{~S}_{6} & \mathrm{~S}_{7} & \mathrm{~S}_{8} & \mathrm{~S}_{9} & \mathrm{~S}_{10}\end{array}\right]^{\mathrm{T}}$

$\underset{\sim}{\mathrm{F}}=\left[\begin{array}{llllllllll}\mathrm{F}_{1} & \mathrm{~F}_{2} & \mathrm{~F}_{3} & \mathrm{~F}_{4} & \mathrm{~F}_{5} & \mathrm{~F}_{6} & \mathrm{~F}_{7} & \mathrm{~F}_{8} & \mathrm{~F}_{9} & \mathrm{~F}_{10}\end{array}\right]^{\mathrm{T}}$

where, $F_{i} i=1,2,3, \cdots, n$ can be defined as:

$F_{2 k-1}=\left\{\begin{array}{cc}2 N_{1,1}^{1} Y_{1}+N_{1,2}^{1} Y_{2}, & k=1 \\ N_{1, m}^{m} Y_{m}+2 N_{1, m+1}^{m} Y_{m+1}, & k=m \\ N_{1, k}^{k} Y_{k}+N_{1, k+1}^{k} Y_{k+1}, & \text { selainnya }\end{array}\right.$

$F_{2 k}=\left\{\begin{array}{cc}2 N_{2,1}^{1} Y_{1}+N_{2,2}^{1} Y_{2}, & k=1 \\ N_{2, m}^{m} Y_{m}+2 N_{2, m+1}^{m} Y_{m+1}, & k=m \\ N_{2, k}^{k} Y_{k}+N_{2, k+1}^{k} Y_{k+1}, & \text { selainnya }\end{array}\right.$

for $\mathrm{k}=1,2,3, \cdots, \mathrm{m}$.

Arithmetic mean, geometric mean and group explicit formulations: To formulate the AM and GM schemes, let consider the system of linear equations in Eq. 11.

Decomposing R into:

$\mathrm{R}=\mathrm{L}+\mathrm{D}+\mathrm{T}$

where, $\mathrm{L}, \mathrm{D}$ and $\mathrm{T}$ are lower triangular matrix, diagonal and upper triangular matrix, respectively. Therefore, AM and GM schemes can be written as (Sulaiman et al., 2005a; 2005b):

${\underset{\sim}{S}}^{(k+1)}=\frac{1}{2}(\underset{\sim}{S^{(1)}}+\underbrace{(2)}_{\sim})$

and:

${\underset{\sim}{S}}^{(k+1)}=\sqrt{{\underset{\sim}{S}}^{(1)} \mathbf{S}^{(2)}}$
Where:

$$
\begin{aligned}
& (\mathrm{D}+\mathrm{rL}) \mathbf{S}^{(1)}=((1-\mathrm{r}) \mathrm{D}-\mathrm{rT}) \boldsymbol{\sim}^{(\mathrm{k})}+\mathrm{rf} \\
& (\mathrm{D}+\mathrm{rT}) \mathrm{S}^{(2)}=((1-\mathrm{r}) \mathrm{D}-\mathrm{rL}) \mathrm{S}^{(\mathrm{k})}+\mathrm{rf}
\end{aligned}
$$

The $\mathrm{r}, \mathrm{k}$ and I represent acceleration parameter, number of iterations and identity matrix, respectively. Implementations of both methods are in Algorithm 1.

Algorithm 1: AM and GM schemes:

1) First step

$$
\begin{aligned}
& \text { a. Assign } \\
& \stackrel{\sim}{\sim}^{(1)} \leftarrow(D+r L)^{-1}((1-r) D-r T){\underset{\sim}{(k)}}^{(k)} r(D+r L)^{-1} f
\end{aligned}
$$

2) Second step
b. Assign

$\mathrm{S}^{(2)} \leftarrow(\mathrm{D}+\mathrm{rT})^{-1}((1-\mathrm{r}) \mathrm{D}-\mathrm{rL}) \mathrm{S}^{(k)}+\mathrm{r}(\mathrm{D}+\mathrm{rT})^{-1} \mathrm{f}$

c. AM Scheme

$\mathrm{S}_{\mathrm{i}}^{(\mathrm{k}+1)} \leftarrow \frac{1}{2}\left(\mathrm{~S}_{\mathrm{i}}^{(1)}+\mathrm{S}_{\mathrm{i}}^{(2)}\right)$

or GM scheme:

$$
S_{i}^{(k+1)} \leftarrow\left\{\begin{array}{cc}
\sqrt{S_{i}^{(1)} S_{i}^{(2)}}, & \text { if }\left(S_{i}^{(1)} S_{i}^{(2)}\right)>0 \\
-\sqrt{S_{i}^{(1)} S_{i}^{(2)}}, & \text { if }\left(S_{i}^{(1)} S_{i}^{(2)}\right)>0 \& S_{i}^{(1)}<0 \\
S_{i}^{(1)}+\sqrt{S_{i}^{(1)} S_{i}^{(2)}}, & \text { if }\left(S_{i}^{(1)} S_{i}^{(2)}\right)<0 \& S_{i}^{(1)}>S_{i}^{(2)} \\
S_{i}^{(2)}+\sqrt{S_{i}^{(1)} S_{i}^{(2)}}, & \text { if }\left(S_{i}^{(1)} S_{i}^{(2)}\right)<0 \& S_{i}^{(1)}<S_{i}^{(2)}
\end{array}\right.
$$

The optimum $r$ value is determined from the lowest number of iterations.

To formulate the EG scheme, the system of linear Eq. 11 has to be decomposed into sub-matrix of $(2 \times 2)$ as follows: 


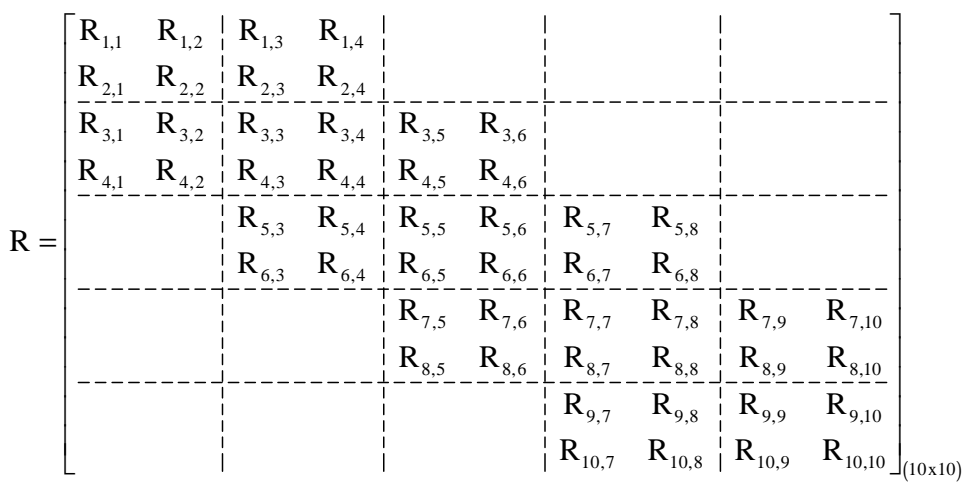

$\mathrm{S}=\left[\begin{array}{ll:ll:ll:ll:ll}\mathrm{S}_{1} & \mathrm{~S}_{2} & \mathrm{~S}_{3} & \mathrm{~S}_{4} & \mathrm{~S}_{5} & \mathrm{~S}_{6} & \mathrm{~S}_{7} & \mathrm{~S}_{8} & \mathrm{~S}_{9} & \mathrm{~S}_{10}\end{array}\right]^{\mathrm{T}}$

$\underset{\sim}{\mathrm{F}}=\left[\begin{array}{ll:ll:ll:ll:ll}\mathrm{F}_{1} & \mathrm{~F}_{2} & \mathrm{~F}_{3} & \mathrm{~F}_{4} & \mathrm{~F}_{5} & \mathrm{~F}_{6} & \mathrm{~F}_{7} & \mathrm{~F}_{8} & \mathrm{~F}_{9} & \mathrm{~F}_{10}\end{array}\right]^{\mathrm{T}}$

Referring to the system of linear Eq. 11, the two point EG scheme can be rewritten as (Evans and Yousif, 1986; Jumat and Abdullah, 2001):

$\left[\begin{array}{cc}R_{i-1, i-1} & R_{i-1, i} \\ R_{i, i-1} & R_{i, i}\end{array}\right]\left[\begin{array}{c}S_{i-1} \\ S_{i}\end{array}\right]=\left[\begin{array}{c}P_{1} \\ P_{2}\end{array}\right]$

Where:

$P_{1}=\left\{\begin{array}{cc}F_{1}-R_{1,3} S_{3}-R_{1,4} S_{4}, & i=1 \\ F_{n-1}-R_{n-1, n-3} S_{n-3}-R_{n-1, n-2} S_{n-2}, & i=n-1 \\ F_{i-1}-R_{i-1, i-3} S_{i-3}-R_{i-1, i-2} S_{i-2}- & i=3,5,7, \cdots, n-3 \\ R_{i-1, i+1} S_{i+1}-R_{i-1, i+2} S_{i+2}, & \end{array}\right.$

$P_{2}=\left\{\begin{array}{cc} & i=2 \\ F_{2}-R_{2,3} S_{3}-R_{2,4} S_{4}, & i=n=2 m \\ F_{n}-R_{n, n-3} S_{n-3}-R_{n, n-2} S_{n-2}, & \\ F_{i}-R_{i, i-3} S_{i-3}-R_{i, i-2} S_{i-2}- & i=4,6,8, \cdots, n-2 \\ R_{i, i+1} S_{i+1}-R_{i, i+2} S_{i+2}, & \end{array}\right.$ as:

Using the matrix approach, Eq. 15 can be rewritten

$$
\begin{aligned}
& {\left[\begin{array}{c}
S_{i-1} \\
S_{i}
\end{array}\right]=} \\
& \frac{1}{\left(R_{i-1, i-1}\right)\left(R_{i, i}\right)-\left(R_{i, i-1}\right)\left(R_{i-1, i}\right)}\left[\begin{array}{cc}
R_{i, i} & -R_{i-1, i} \\
-R_{i, i-1} & R_{i-1, i-1}
\end{array}\right]\left[\begin{array}{l}
P_{1} \\
P_{2}
\end{array}\right]
\end{aligned}
$$

However, the two point EG scheme in Eq. 16 still cannot be implemented using computer program since the determinant value is to small relatively, i.e.:

$$
\left(\mathrm{R}_{\mathrm{i}-1, \mathrm{i}-1}\right)\left(\mathrm{R}_{\mathrm{i}, \mathrm{i}}\right)-\left(\mathrm{R}_{\mathrm{i}, \mathrm{i}-1}\right)\left(\mathrm{R}_{\mathrm{i}-1, \mathrm{i}}\right) \approx 0
$$

Therefore, we rewrite the system of linear Eq. 15 as:

$\left[\begin{array}{ll}\alpha & 1 \\ \beta & 1\end{array}\right]\left[\begin{array}{c}\mathrm{S}_{\mathrm{i}-1} \\ \mathrm{~S}_{\mathrm{i}}\end{array}\right]=\left[\begin{array}{l}\rho_{1} \\ \rho_{2}\end{array}\right]$

Where:

$\alpha=\frac{\mathrm{R}_{\mathrm{i}-1, \mathrm{i}-1}}{\mathrm{R}_{\mathrm{i}-1, \mathrm{i}}}>1$

$\beta=\frac{R_{i, i-1}}{R_{i, i}}<1$

$\rho_{1}=\frac{P_{1}}{R_{i-1, i}}$

$\rho_{2}=\frac{P_{2}}{R_{i, i}}$

Using the Gauss elimination technique to Eq. 18, it can be shown that the coefficient matrix can be rewritten in the form of triangular matrix as:

$\left[\begin{array}{cc}1 & 0 \\ -\frac{\beta}{\alpha} & 1\end{array}\right]\left[\begin{array}{cc}\alpha & 1 \\ \beta & 1\end{array}\right]\left[\begin{array}{c}\mathrm{S}_{\mathrm{i}-1} \\ \mathrm{~S}_{\mathrm{i}}\end{array}\right]=\left[\begin{array}{cc}1 & 0 \\ -\frac{\beta}{\alpha} & 1\end{array}\right]\left[\begin{array}{l}\rho_{1} \\ \rho_{2}\end{array}\right]$

$\left[\begin{array}{cc}\alpha & 1 \\ 0 & 1-\frac{\beta}{\alpha}\end{array}\right]\left[\begin{array}{c}S_{i-1} \\ S_{i}\end{array}\right]=\left[\begin{array}{c}\rho_{1} \\ \rho_{2}-\frac{\beta}{\alpha} \rho_{1}\end{array}\right]$

Manipulating both Eq. 19, it can be shown that the two point EG scheme with parameter w (denoted as 2 point-EG (SOR)) at $(\mathrm{k}+1)^{\text {th }}$ iteration as:

$\left[\begin{array}{c}S_{i-1} \\ S_{i}\end{array}\right]^{(k+1)}=(1-w)\left[\begin{array}{c}S_{i-1} \\ S_{i}\end{array}\right]^{(k)}+\frac{w}{\alpha-1}\left[\begin{array}{c}\rho_{1}-\rho_{2} \\ \alpha \rho_{2}-\rho_{1}\end{array}\right], \quad \alpha>1$ 
Am. J. Applied Sci., 7 (7): 969-975, 2010

with $1 \leq \mathrm{w}<2$. The implementation of 2 point- EG (SOR) is displayed in Algorithm 2.

Algorithm 2: 2 point-EG (SOR) scheme:

a. Initialize

parameter

$\mathrm{R}, \quad \mathrm{F}, \quad \mathrm{S}_{\mathrm{i}}^{(0)}, \quad \mathrm{w}, \quad \mathrm{EPSc} \leftarrow 5.0 \mathrm{E}-6$

b. For $\mathrm{k}=1,2,3, \cdots, \mathrm{m}$, calculate

i. Assign $\rho_{1}, \rho_{2}$

ii. $\begin{aligned} \text { Calculate } & \left(\frac{\mathrm{w}}{\alpha-1}\right)\left(\rho_{1}-\rho_{2}\right) \\ & S_{2 \mathrm{k}}^{(\mathrm{k}+1)} \leftarrow(1-\mathrm{w}) S_{2 \mathrm{k}}^{(\mathrm{k})}+ \\ & \left(\frac{\mathrm{w}}{\alpha-1}\right)\left(\alpha \rho_{2}-\rho_{1}\right)\end{aligned}$

c. Test convergence for $\mathrm{r} i=1,2, \cdots, \mathrm{n}$, calculate $\left|\mathrm{S}_{\mathrm{i}}^{(\mathrm{k}+1)}-\mathrm{S}_{\mathrm{i}}^{(\mathrm{k})}\right|<$ EPS

d. Repeat b if convergence test is not satisfied

In this research, Gauss-Seidel (GS) iterative scheme will be used as the control of comparison.

\section{RESULTS AND DISCUSSION}

Numerical experiment: In this research, we analyze the accuracy of the approximation via both piece-wise polynomial models of Eq. 1 and 2 and compare with the observed data. Furthermore, some numerical experiments have been done to show the performance of AM, GM and EG methods to calculate the $S_{i}$ for $\mathrm{i}=1,2,3, \ldots,(\mathrm{n}=2 \mathrm{~m})$. Results of the numerical experiments for number of iterations, computation time and percentage of average error are given in Fig. 1-3.

Generally, in this research, we use the tolerance error, $\varepsilon=5 \times 10^{-6}$. In the result, we use GS-Linear, AM-Linear, GM-Linear, 2EG(SOR)-Linear, GS-RK, AM-RK, GM-RK and 2EG(SOR)-RK notation to represent the Gauss-Seidel using piece-wise linear polynomial, Arithmetic mean using piece-wise linear polynomial, Geometric mean using piece-wise linear polynomial, 2 point EG(SOR) using piece-wise linear polynomial, Gauss-Seidel using Piece-wise RedlichKister polynomial, Arithmetic mean using Piece-wise Redlich-Kister polynomial, Geometric mean using Piece-wise Redlich-Kister polynomial and 2 point EG(SOR) using Piece-wise Redlich-Kister polynomial, respectively.

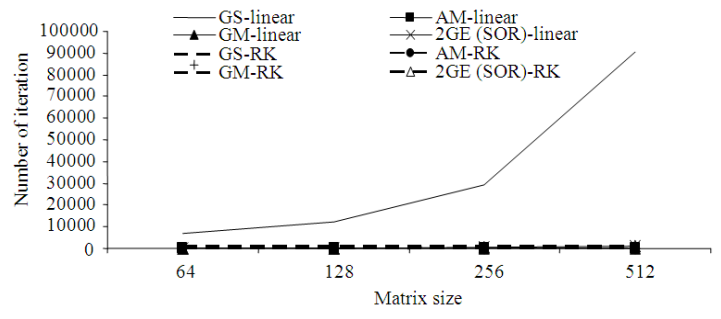

Fig. 1: Comparison of iteration number for all method

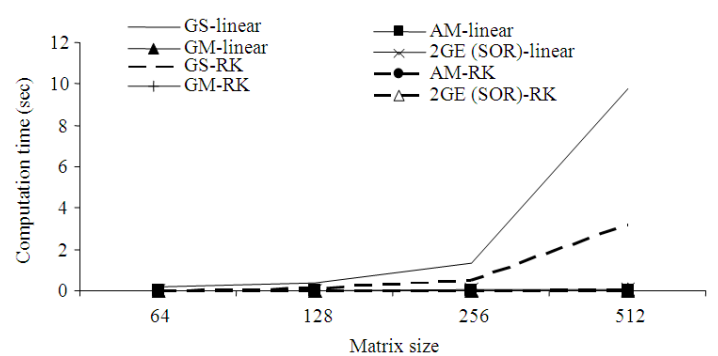

Fig. 2: Comparison of computational time for all method

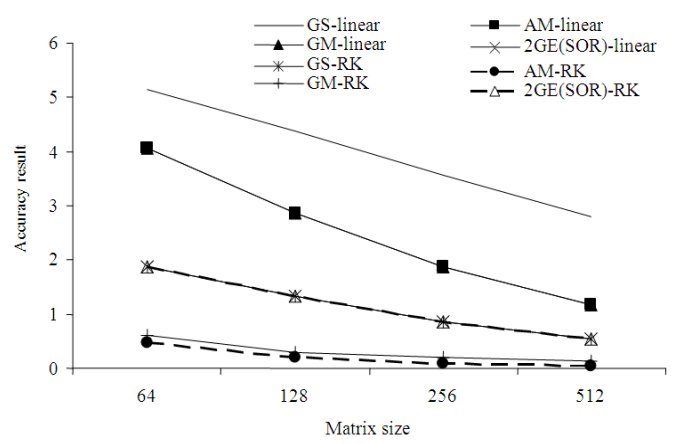

Fig. 3: Percentage of relative average error comparison between methods

\section{CONCLUSION}

In this research, formulation of polynomial model for Eq. 1 and 2 can be represented as Eq. 3. Using polynomial in Eq. 3, the system of linear equations generated for both polynomial models can be shown. However, the condition of the coefficient matrix of Eq. 11 is ill (Chiam and Majid, 1990). Therefore, the convergence criteria may not be satisfied. Furthermore, the coefficient matrix is not categorized as positive definite matrix. Thus, a modification has been proposed via Gauss elimination approach.

From the numerical experiment results, Fig. 1 clearly shows that number of iterations for 2 point EG(SOR)-Linear and 2 point EG(SOR)-RK reduce around 98.12-98.39\% and 98.22-99.07\%, respectively, when compared to GS-Linear. While computational 
time in Fig. 2 for both 2 point EG (SOR) schemes reduce around $88.23-99.28 \%$ and $94.87-100 \%$. Accuracy results in Fig. 3 show the use of piece-wise third order Redlich-Kister polynomial has high accuracy compared to only using linear polynomial.

Both AM and GM schemes also show tremendous results compared to GS schemes. Figure 1 shows that 99.88-99.97\% reduction in number of iterations for AM-Linear and GM-Linear compared to GS-Linear, $77.15-92.57 \%$ reduction in number of iterations for AM-RK and 89.31-92.83\% reduction for GM-RK. Both AM and GM schemes computational time are almost $100 \%$ faster than both GS schemes (Fig. 2). Accuracy results for AM and GM Redlich-Kister scheme are far better than linear polynomial schemes as shown in Fig. 3.

Our next research will be implementing halfsweep (Abdullah, 1991; Ibrahim and Abdullah, 1995), quarter-sweep (Othman and Abdullah, 2000a; 2000b) concept and multigrid (Hackbusch, 1983; Othman and Abdullah, 1999) to solve the same problem.

\section{REFERENCES}

Abdullah, A.R., 1991. The four point Explicit Decoupled Group (EDG) method: A fast Poison solver. Int. J. Comput. Math., 38: 61-70. DOI: 10.1080/00207169108803958

Chiam, T.C. and A.A. Majid, 1990. Numerical Method. USM Press, ISBN: 983-861-016-X, pp: 100.

Evans, D.J., 1985. Group explicit iterative methods for solving large linear systems. Int. J. Comput. Math., 17: 81-108. DOI: 10.1080/00207168508803452

Evans, D.J. and W.S. Yousif, 1986. Explicit group iterative methods for solving elliptic partial differential equations in 3-space dimensions. Int. J. Comput. Math., 18: 323-340. DOI: 10.1080/00207168608803498

Evans, D.J. and W.S. Yousif, 1990. The explicit block relaxation method as a grid smoother in the multigrid v-cycle scheme. Int. J. Comput. Math., 34: 71-78. DOI: 10.1080/00207169008803864

Hackbusch, W., 1983. Introduction to Multi-grid Methods for the Numerical Solution of Boundary Value Problems. In: Computational Methods for Turbulent, Transonic and Viscous Flows, Dlm. Essers, J.A. (Ed.). Springer-Verlag, Berlin, ISBN: 0891162739, pp: 45-92.

Ibrahim, A. and A.R. Abdullah, 1995. Solving the twodimensional diffusion equation by the four point Explicit Decoupled Group (EDG) iterative method. Int. J. Comput. Math., 58: 253-256. DOI: $10.1080 / 00207169508804434$
Jumat, B.S. and A.R.B. Abdullah, 1999. Some explicit decoupled group iterative method with half-sweep multigrain for Poisson's equation. Sains Malaysia, 28: 161-172.

Jumat, S. and A.R. Abdullah, 2001. Finite element method using group explicit iterative method for one dimensional diffusion problem. J. Kejuruteraan, 13: 41-49.

Muthuvalu, M.S. and J. Sulaiman, 2008. Half-Sweep Geometric Mean method for solution of linear Fredholm equations. Matematika, 24: 75-84.

Othman, M. and A.R. Abdullah, 1999. An Efficient Multigrid Poisson Solver. Int. J. Computer Math., 71: 541-553. DOI: 10.1080/00207169908804828

Othman, M. and A.R. Abdullah, 2000a. An efficient four points modified explicit group Poison solver. Int. J. Comput. Math., 76: 203-217. DOI: $10.1080 / 00207160008805020$

Othman, M. and A.R. Abdullah, 2000b. An efficient parallel quarter-sweep point iterative algorithm for solving poison equation on SMP parallel computer. Pertanika J. Sci. Technol., 8: 161-174.

Ruggiero, V. and E. Galligani, 1990. An iterative method for large sparse systems on a vector computer. Comput. Math. Applied, 20: 25-28. DOI: 10.1016/0898-1221(90)90065-R

Sahimi, M.S. and M. Khatim, 2001. The Reduced Iterative Alternating Decomposition Explicit (RIADE) method for the solution of the heat conduction equation. Pertanika J. Sci. Technol., 9: 3-20.

Sulaiman, J., M. Othman and M.K. Hasan, 2004. A new Half-Sweep Arithmetic Mean (HSAM) algorithm for two-point boundary value problems. Proceedings of the International Conference on Statistics and Mathematics and its Application in the Development of Science and Technology, Oct. 2004, Bandung, Indonesia, pp: 169-173.

Sulaiman, J., M. Othman and M.K. Hasan, 2005a. Half-sweep arithmetic mean method using finite element approximation for Poisson's equation. Proceedings of the International Conference on Applied Mathematics, Aug. 2005, In CD Form, Bandung Institute of Technology, Indonesia.

Sulaiman, J., M. Othman and M.K. Hasan, 2005b. A fourth-order finite difference solver for Poisson's equations via the Half-Sweep Arithmetic Mean (HSAM) method. Proceedings of the First IMT-GT Regional Conference on Mathematics, Statistics and their Applications, Nov. 2005, Indonesia, pp: 139-146. 
Sulaiman, J., M.H. Abdullah, A. Saudi, M.K. Hasan and M. Othman, 2006a. A numerical simulation on water quality model using half-sweep geometric mean method. Proceedings of the 2nd Southeast Asian Natural Resources and Environmental Management Conference, Nov. 2006, pp: 25-29.

Sulaiman, J., M. Othman, N. Yaacob and M.K. Hasan, 2006b. Half-Sweep Geometric Mean (HSGM) method using fourth-order finite difference scheme for two-point boundary problems. Proceedings of the 1st International Conference on Mathematics and Statistics, June 2006, Indonesia, pp: 25-33.

Sulaiman, J., M. Othman and M.K. Hasan, 2007. Redblack EDGSOR iterative method using triangle element approximation for 2D Poisson equations. Lecture Notes Comput. Sci., 4707: 298-308.
Yousif, W.S. and D.J. Evans, 1986. Explicit group over-relaxation methods for solving elliptic partial differential equations. Math. Comput. Simulat., 28: 453-466. DOI: 10.1016/0378-4754(86)90040-6

Yousif, W.S. and D.J. Evans, 1995. Explicit de-coupled group iterative methods and their implementations. Paral. Algorithms Appli., 7: 53-71. DOI: 10.1080/10637199508915522

Yousif, W.S. and D.J. Evans, 1998. New point and group iterative methods for solving three dimensional elliptic equations. Int. J. Comput. Math., 66: 353-362. DOI: $10.1080 / 00207169808804646$ 